MLM- -3704

DE92 001604

\title{
Maximum Credible Event Determination for the Surveillance Powder Samples and Their Handling Containers
}

Robert B. Jones and James D. Cogan, Jr.

September 19, 1991

\section{MOUND}

operated by

I EERE MOUND APPLIED TECHNOLOGIES

P.O. Box 3000, Miamisburg, Ohio 45343-3000

for the

U. S. DEPARTMENT OF ENERGY

Contract No. DE-AC04-88DP43495 


\section{DISCLAIMER}

This report was prepared as an account of work sponsored by an agency of the United States Government. Neither the United States Government nor any agency thereof. nor any of their employees, makes any warranty. express or implied. or assumes any legal llability or responslbility for the accuracy. completeness. or usefulness of any information. apparatus. product. or process disclosed. or represents that its use would not infringe privately owned rights. Reference herein to any specific commerclal product. process. or service by trade name. trademark. manufacturer. or otherwiso. does not necessarily constitute or imply its endorsement. recommendation. or favoring by the United States Government or any agency thereof. The vlews and opinions of authors expressed herein do not necessarlly state or reflect those of the United States Government or any agency thereof.

This report has been reproduced directly from the best avallable copy.

Avallable to DOE and DOE contractors from:

Office of Sclentific and Technical Information

P.O. Box 62

Oak Ridge. TN 37831

Prices avallable from (615)576-8401. FTS 626-8401

Avallable to the public from:

National Technical Information Service

U.S. Department of Commerce

5285 Port Royal Rd.

Springfleld. VA 22161 
MLM-3704

UC-741

\section{Maximum Credible Event Determination for the Surveillance Powder Samples and Their Handling Containers}

Robert B. Jones and James D. Cogan, Jr.

Issued: September 19, 1991

\section{MOUND}

operated by

EERE MOUND APPLIED TECHNOLOGIES

P.O. Box 3000. Miamisburg, Ohio 45343-3000

for the

U. S. DEPARTMENT OF ENERGY

Contract No. DE-AC04-88DP43495 


\section{Contents}

page

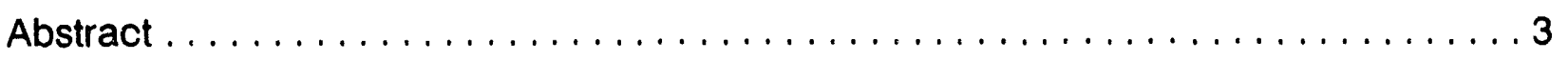

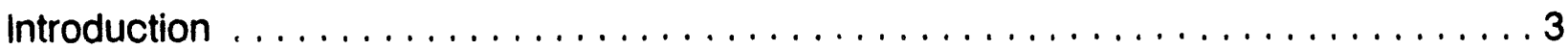

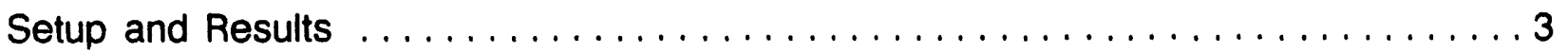

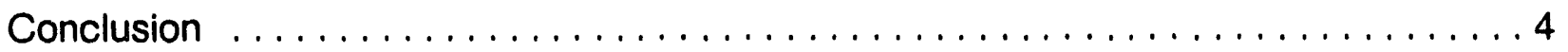




\section{Abstract}

An investigation was done to determine the maximum credible event value for samples of explosives and disassembled components up to $1.2 \mathrm{~g}$ when stored in conductive plastic vials as packaged and handled, stored, or transported at Mound. The test was performed at Test Firing, with photographs taken before and after the test. The standard propagation test setup was used; a vial containing $1.2 \mathrm{~g}$ of PETN (pentaerythritol tetranitrate) was surrounded by other like vials containing 1.2-g samples of PETN. The 1.2-g PETN pellet was then ignited by an EX-12 detonator. The test showed that there was no propagation and that the maximum credible event value for the handling tray is $1.2 \mathrm{~g}$. The test also showed that when the tray is placed in a metal container the MCE value will still be $1.2 \mathrm{~g}$.

\section{Introduction}

For packaging and handling, transportation, or storage, samples of explosives and disassembled components will be placed in one of three different sizes of a conductive plastic vial: 1 by $2 \frac{1}{8}$ in., 1 by $13 / 8$ in., or $1 \frac{3}{4}$ by $7 / 8$ in. The vials will be placed in styrofoam trays painted with black conductive paint. The trays will hold from 32 to 45 sample vials, depending on the size of the vial. Two of these trays will be placed in an aluminum suitcase. Mound DWG 5-1173.

To meet the requirements of the Mound Energetic Materials Safety Handbook, all explosive components and their handling trays and storage containers must have their maximum credible event (MCE) value certified. The MCE value for an explosive sample in a conductive plastic vial is the weight (up to $1.2 \mathrm{~g}$ ) of energetic material it contains when in its nonpropagating handling tray. The MCE value is also $1.2 \mathrm{~g}$ when two nonpropagating handling trays are placed in a metal container for transportation or storage. For an MCE value of $0.00 \mathrm{~g}$, the metal container must be banded to contain any fragments.

\section{Setup and Results}

Because insufficient data were available to determine the MCE value by analogy to other similar explosive samples, a propagation test was done. The propagation test was required to determine the maximum credible event value that would be assigned to the explosives samples generated by Surveillance. Samples of explosives up to $1.2 \mathrm{~g}$ will be placed in conductive plastic vials. put in handling trays in metal containers, and stored. Figures 1 through 5 show the setup of the test. Figure 1 shows a 1.2-g PETN pellet with an EX-12 detonator glued to it. Figure 2 shows the bottom tray with one plastic vial containing $1.2 \mathrm{~g}$ of PETN and the top tray with eight vials containing $1.2 \mathrm{~g}$ of PETN. Figure 3 shows the pellet assembly placed in a conductive plastic vial surrounded by eight other sample vials, each containing $1.2 \mathrm{~g}$ of PETN. Figure 4 sinows the sample container to be detonated with its lid in place, a firing cable attached, and the cable taped to the tray for stability. The metal container, ready for testing, is shown in Figure 5. The firing cable extends out of the metal container above the handle. 
The results of detonating the 1.2-g sample of PETN in a plastic vial are shown in Figures 6 through 9. These figures show the damage to the metal container and the vials after testing. Figure 6 is a view of the container in the testfiring chamber after the test. The container lid was blown open and significant damage was done to the plastic vials. One vial was blown out of the container with its lid detached. Figure 7 is a closeup of the top tray and the remaining vials. All the vials were accounted for. Figure 8 shows the damage done to the bottom tray. The plastic vial under the explosive sample that was detonated was destroyed. In addition to the remains of the plastic vials in the bottom tray, the photograph shows the bits of the explosive pellet and fragments of the plastic vial that were found. Figure 9 shows the damage to the bottom of the container. A small dent was observed in the bottom. A larger dent was also noted in the lid above the sample vial that had contained the PETN pellet which was detonated.

\section{Conclusion}

The test proved that there was no propagation, although the unbanded container did not contain all fragments. An evaluation of the test results determined that the MCE value for the handling tray was $1.2 \mathrm{~g}$. When the handling tray is placed in a metal container the MCE value will still be $1.2 \mathrm{~g}$. For an MCE value of $0.00 \mathrm{~g}$, the container will have to be banded to keep all fragments contained. 


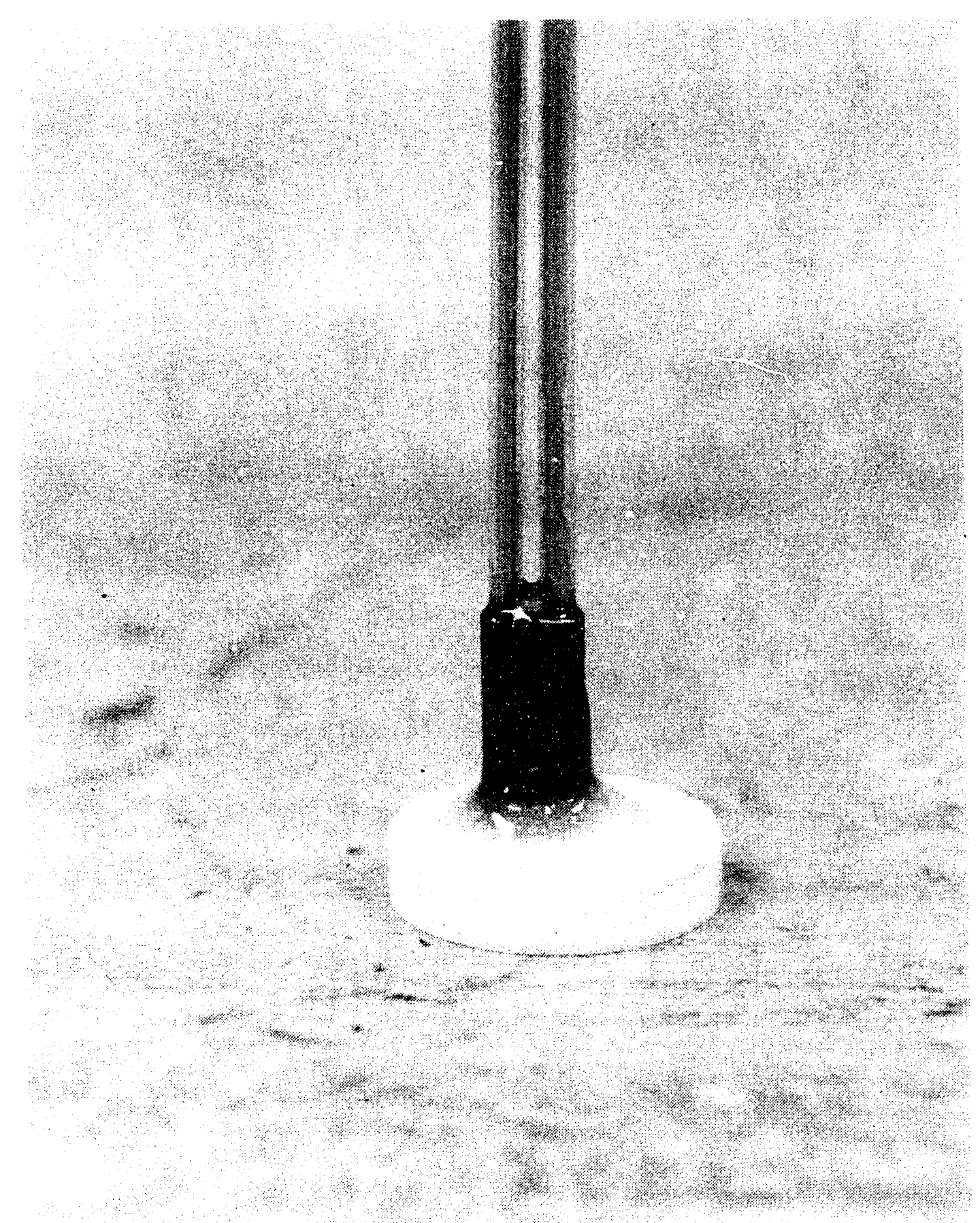

Figure 1 - View of 1.2-g PETN pellet with EX-12 detonator glued to top surface. 


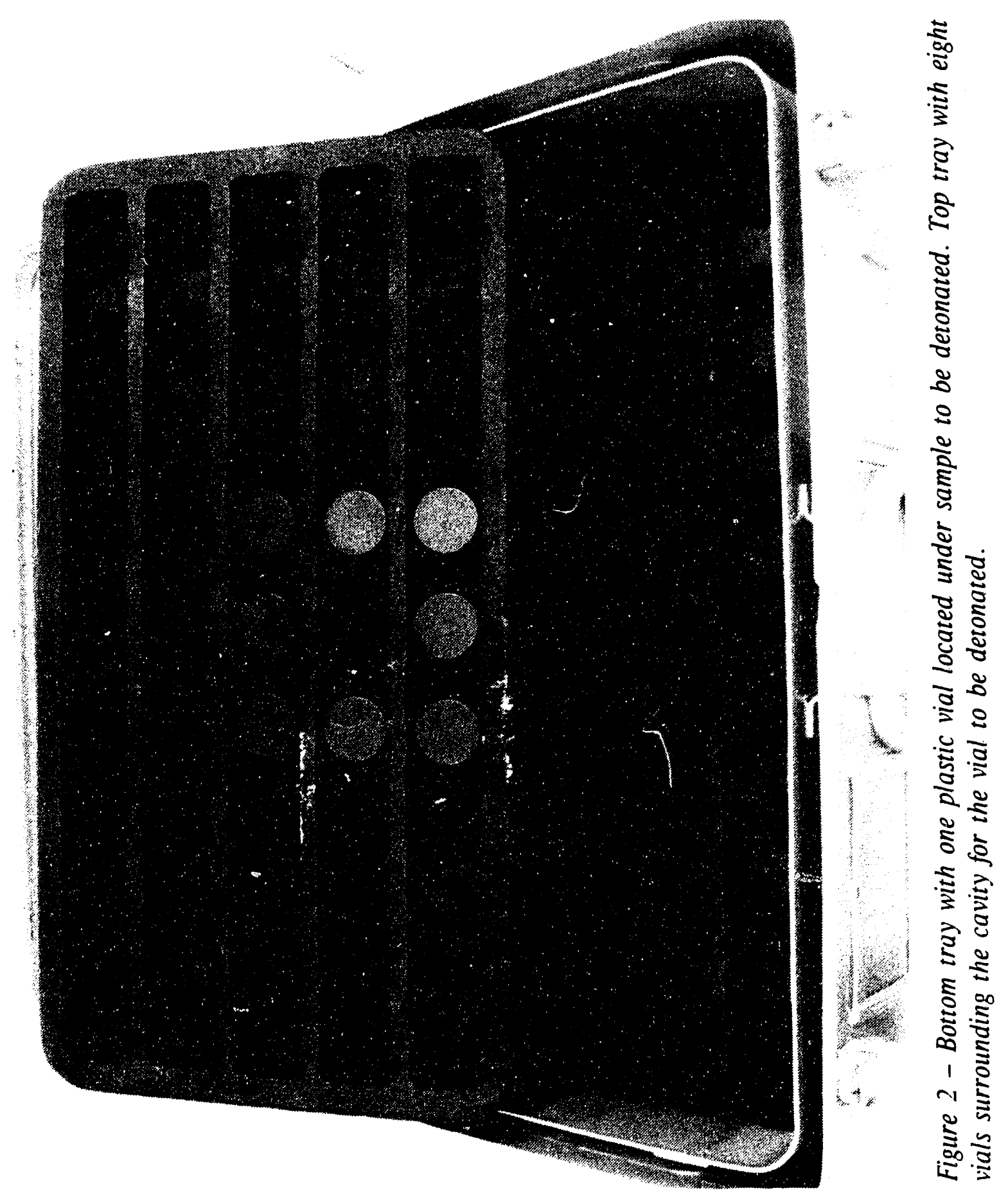




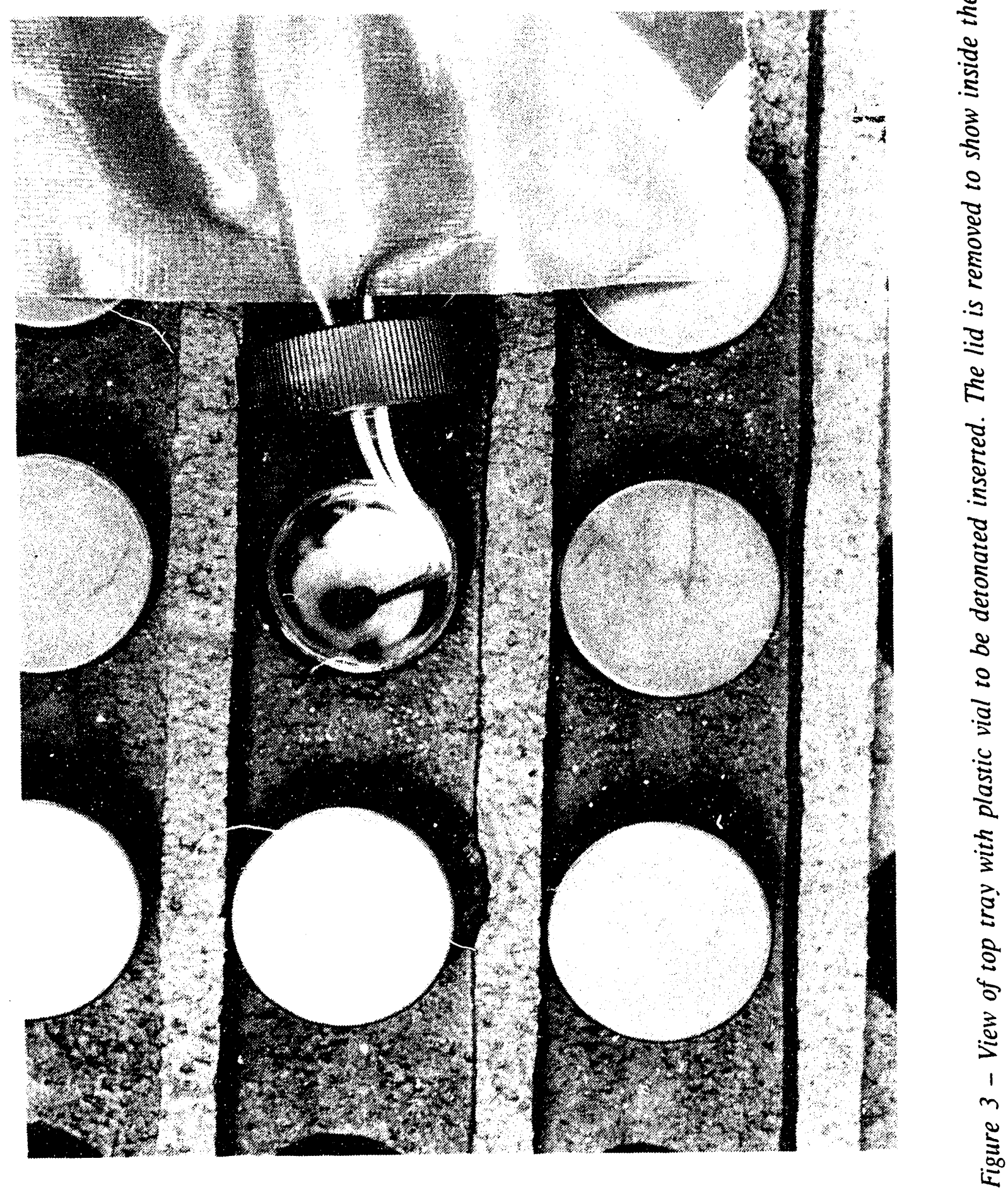




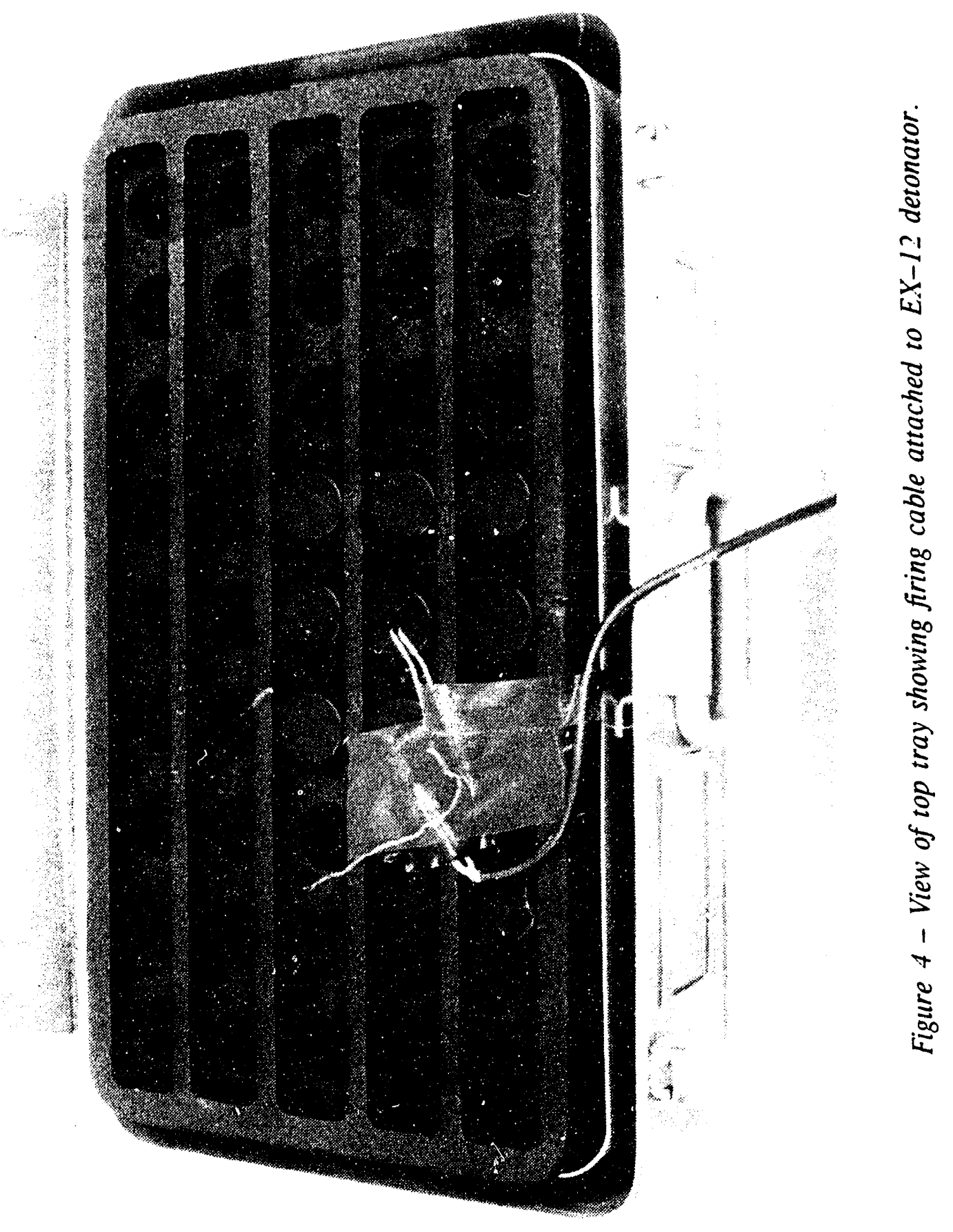




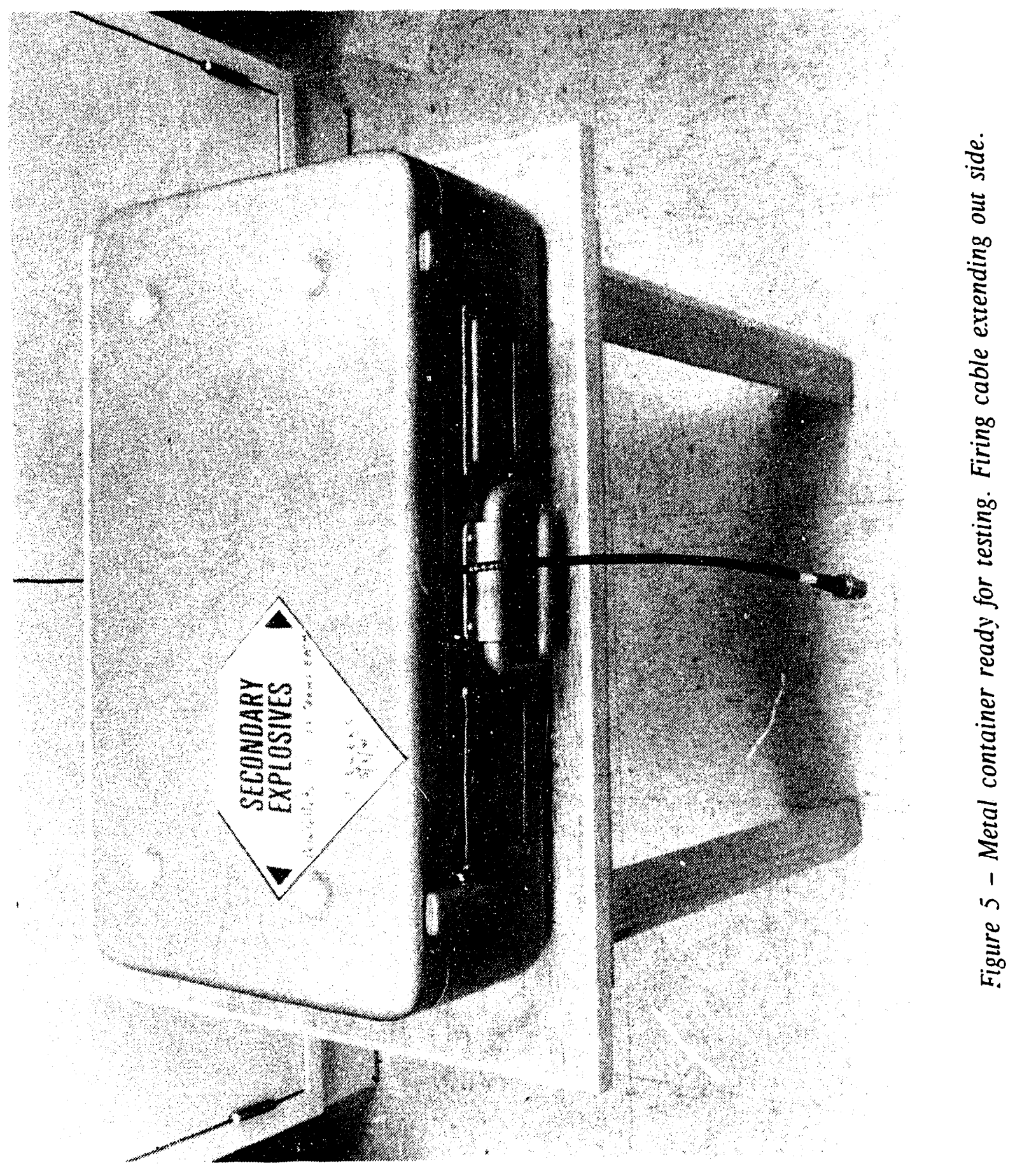




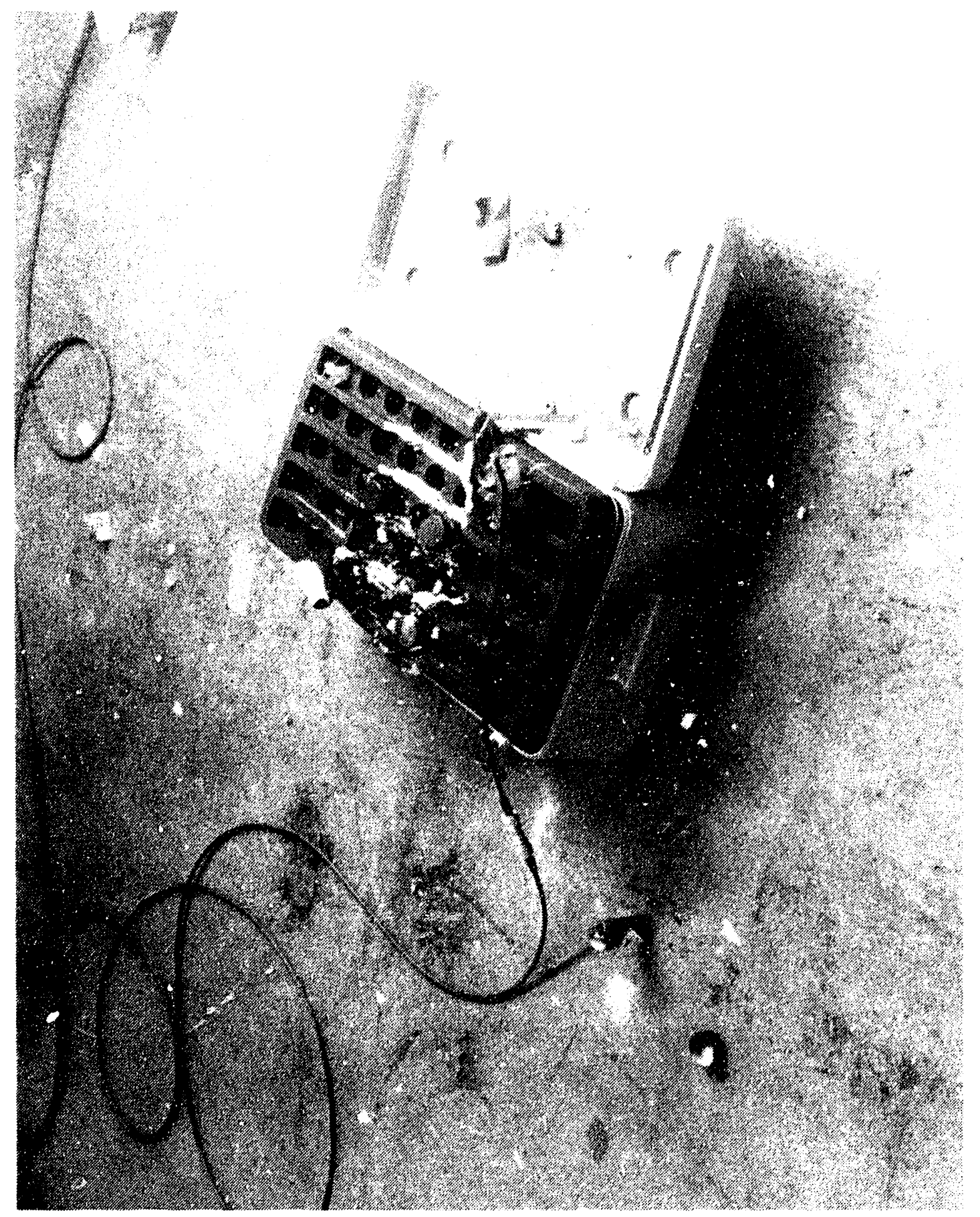

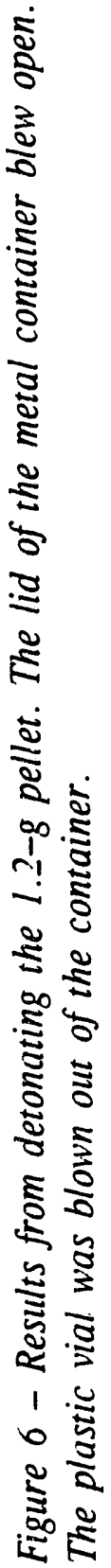




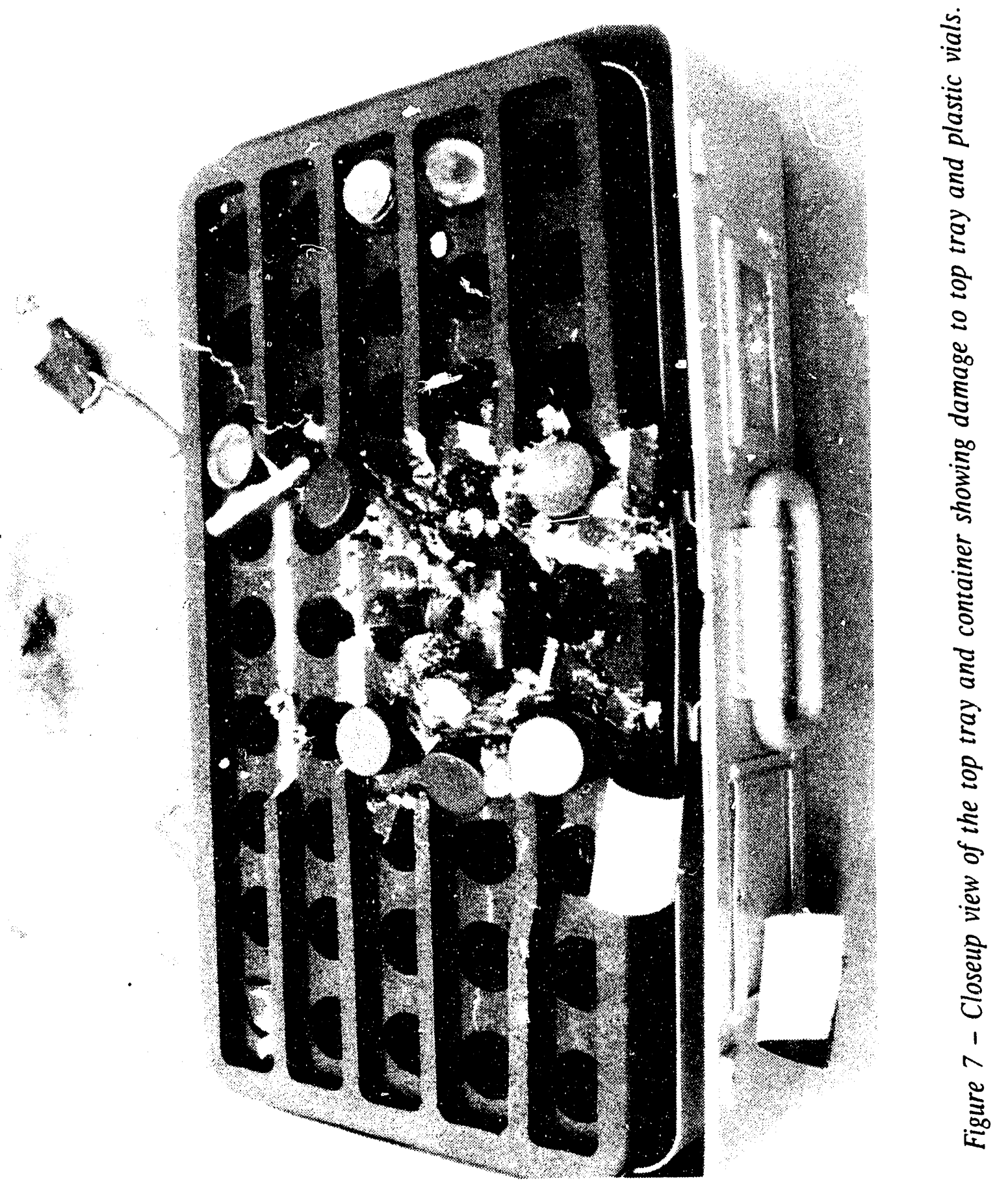




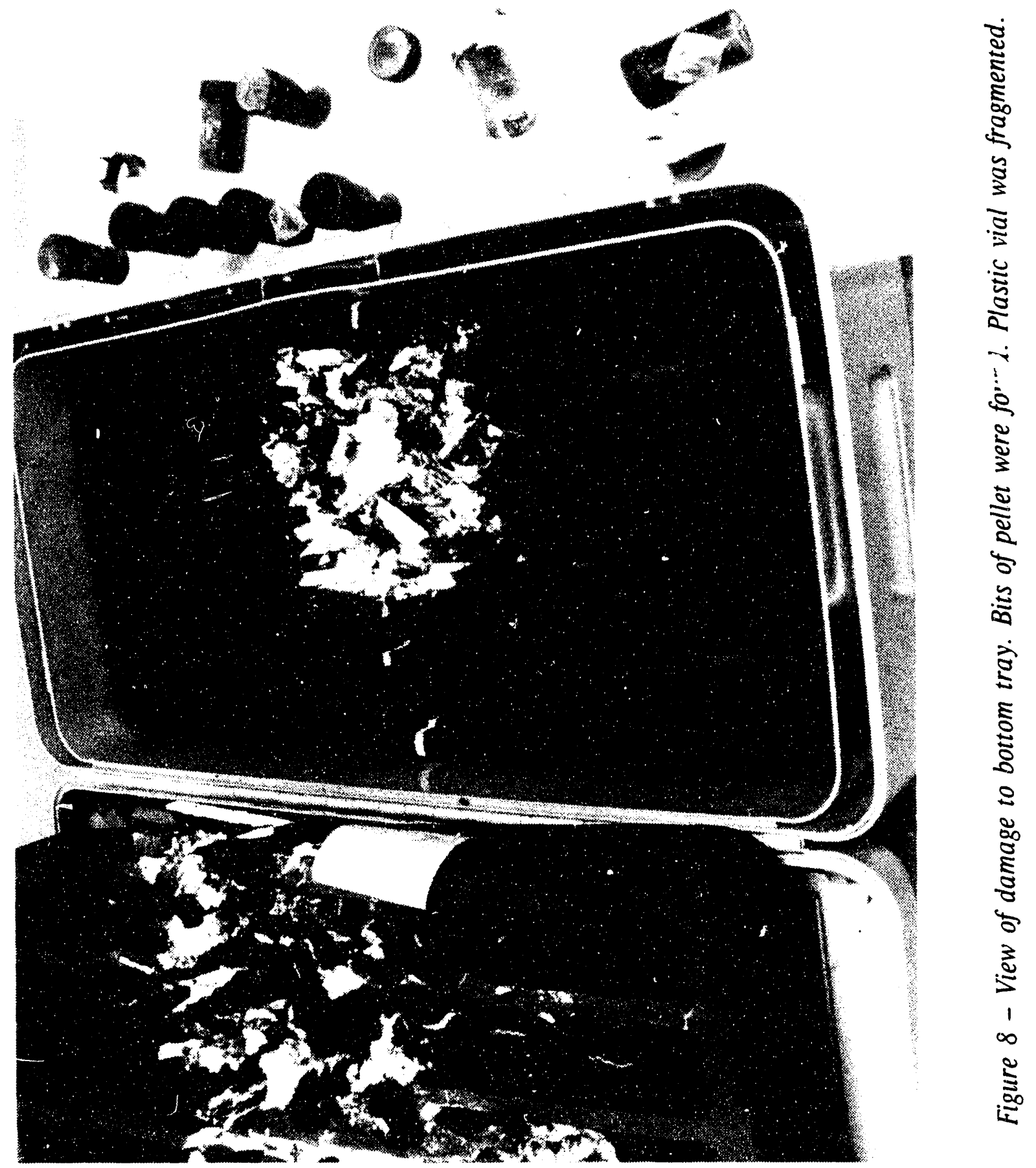




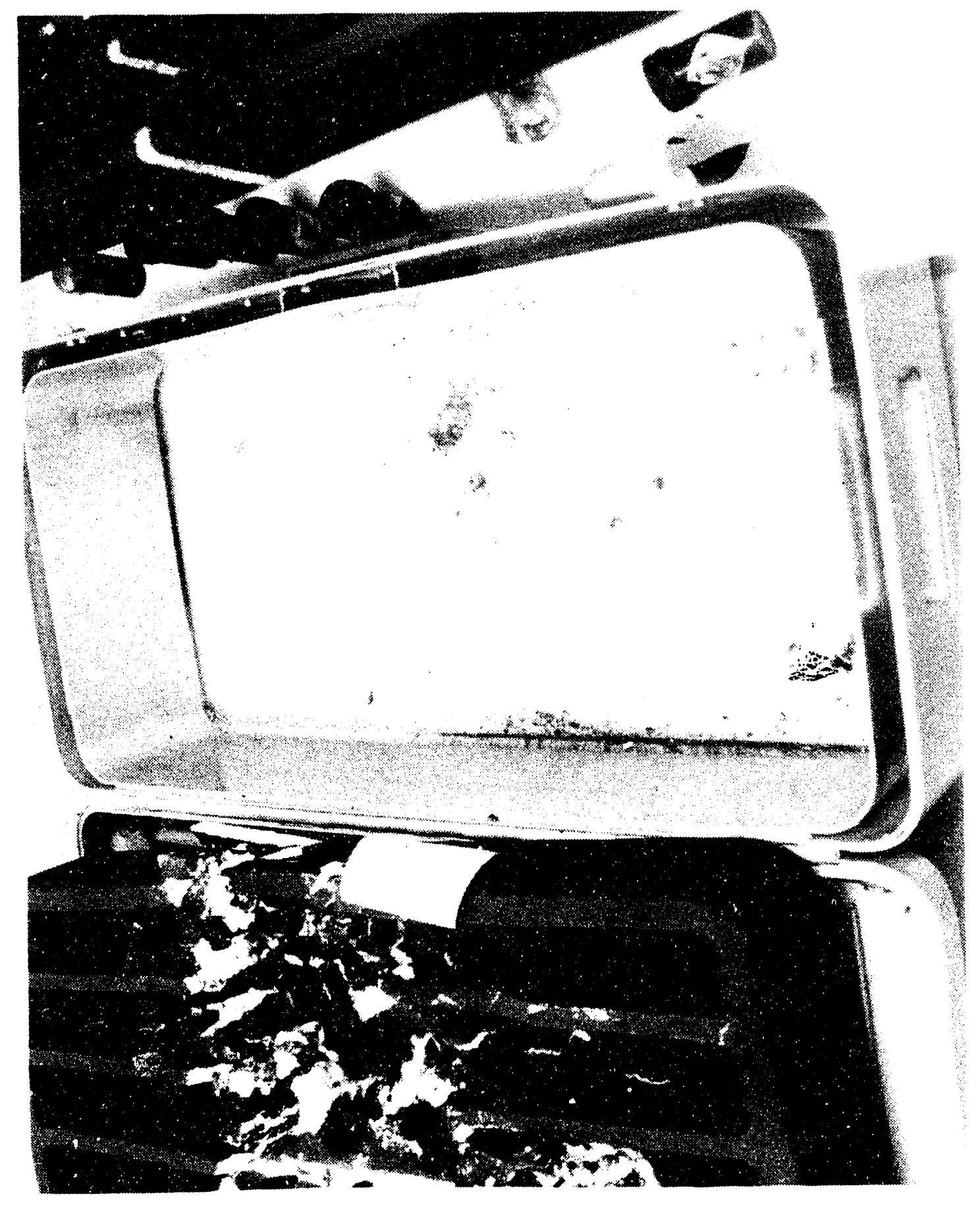

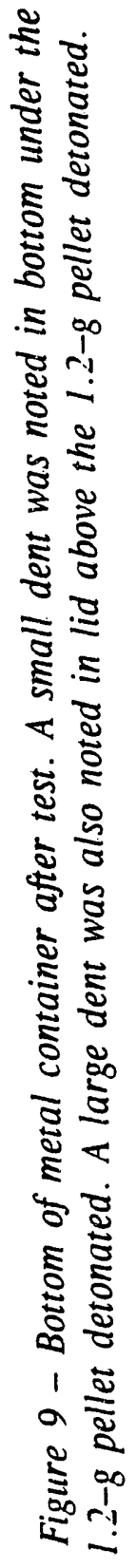




\section{Distribution}

\section{External}

OSTI, UC-741 (35)

A. R. Griego, DOE/AL

M. G. Hawk, GEND

J. A. Morley, DOE/DAO

\section{Internal}

M. E. Babcock

T. M. Bruggeman

R. D. Burnett

J. D. Cogan

P. B. Dowd

T. K. Ferguson

R. J. Finney

R. A. Fischbein

L. D. Haws

J. A. Helgerson

E. D. Hill

R. B. Jones (5)

F. G. Krach

D. E. Michel

G. L. Numbers

G. E. Round

W. H. Smith

R. E. Vallee

H. A. Woltermann

Library (10)

Publications

Mary J. Pacinda, Editor

Technical Publications 

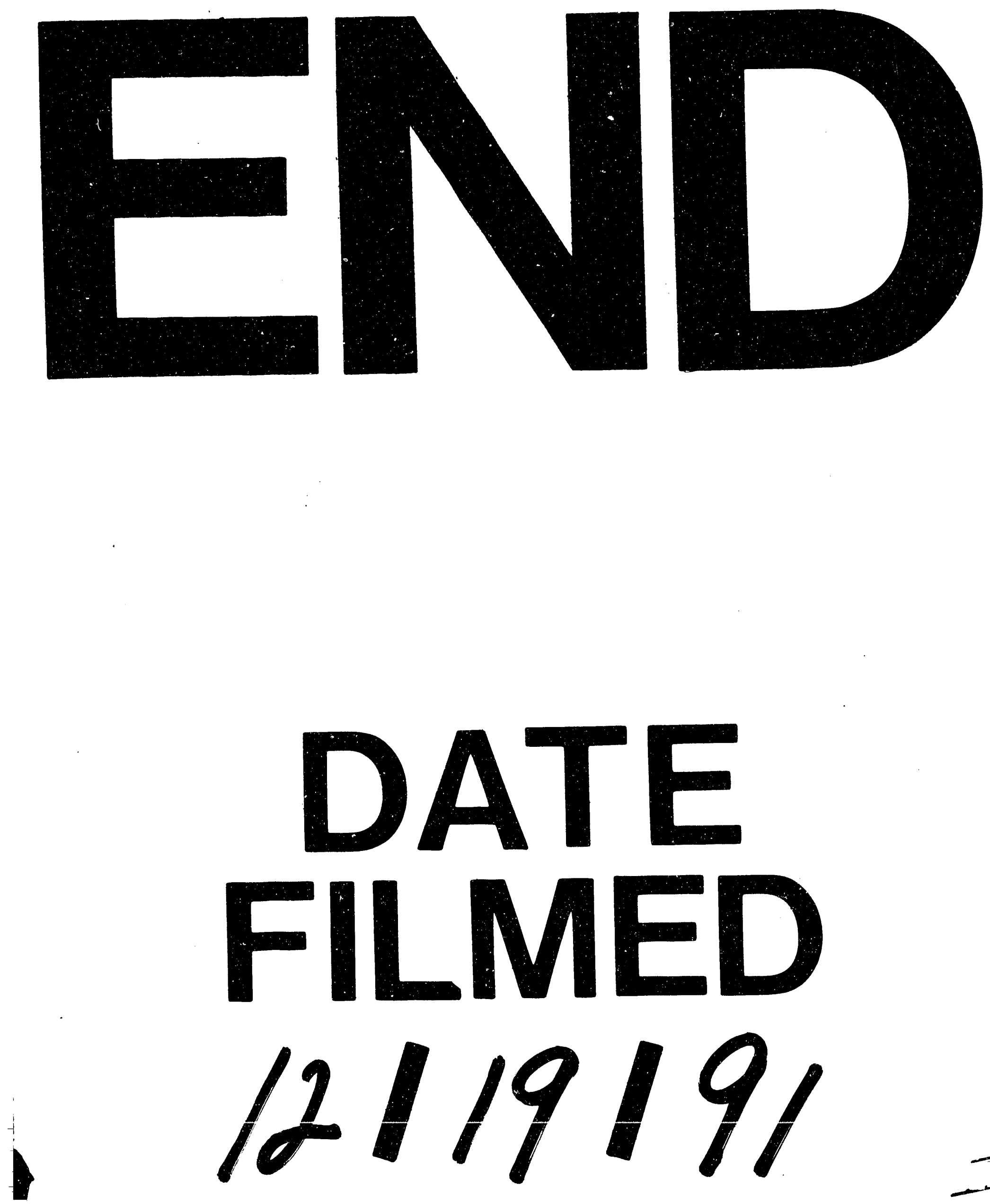
